\title{
Environmental factors associated with drowning prevention knowledge of parents in Bangladesh: a randomized controlled trial
}

Dr Mosharaf Hossain ( $\sim$ md.hossain@umt.edu.my )

Universiti Malaysia Terengganu

Dr Kulanthayan KC Mani

Universiti Malaysia Terengganu

\section{Research article}

Keywords: Environmental factors, SMS intervention, Knowledge of patents on drowning prevention and Bangladesh.

Posted Date: July 28th, 2020

DOI: https://doi.org/10.21203/rs.3.rs-39470/v1

License: @ (i) This work is licensed under a Creative Commons Attribution 4.0 International License. Read Full License 


\section{Abstract}

Background Drowning is the third leading cause of death for children aged 0-4 years in many Asian countries, and is a serious but neglected health problem in low and middle-income countries (LMICs) like Bangladesh. In Bangladesh, drowning rates are 10 to 20 times more than those in other developed countries. The aim of the effectiveness of a mobile SMS intervention to improve the environmental knowledge of parents of children aged under five concerning the prevention of drowning.

Methods Design: a cluster randomized community trial with 788 parents of children aged under five in a rural community of Bangladesh. Intervention: Mobile SMS intervention for parents of children under five years concerning the prevention of drowning. Outcome: association in environmental knowledge of parents concerning the prevention of drowning between the baseline and immediate follow-up after the intervention, and after three months.

Results There was a significant improvement in environmental knowledge in the intervention group compared to the control group at different at baseline, immediately after intervention and 3-months after intervention. The associated factors for drowning included the time (11:00am-2:00 pm), lack of swimming ability, parents who were not aware about childhood drowning, unwanted ditches that were not filled in, lack of medical facilities, and lack of information through mass media for the prevention of childhood drowning.

Conclusion Special programmes and training could be increase knowledge about childhood drowning prevention in Bangladesh and should be broadcast on the radio and television networks.

Trial registration: Current Controlled Trials ISRCTN13774693, 08/03/2015.

\section{Background}

Drowning, which can be defined as mortality arising from injury of the respiratory function as a result of immersion in liquid, is the main reason of mortality globally. It has been predicted that, in 2000, 449,000 inhabitants drowned globally. It is the third highest cause of mortality in children aged under five years, and the top cause of mortality due to injury, with the mortality rates in male children being almost twice as high as those in female children ${ }^{1}$. Bangladesh is a largely rural low-income country with most households located near bodies of water ${ }^{2}$. Children who live close to ponds, rivers, and lakes, and the poor in society constitute the highest number of victims. More than two-thirds of the country's waterholes are the main bathing place for 160 million people ${ }^{3}$. In Bangladesh, drowning is the leading cause of mortality after infancy, $43 \%$ of drowning's occur between the ages under five years ${ }^{4} 60 \%$ of drowning's happen between 9 am and $1 \mathrm{pm}, 80 \%$ of drowning mortalities occur in ponds, ditches, buckets, and drums, $80 \%$ and happen within 20 metres of the house $^{5}$. The incidence of drowning among children aged under five years old was 157 per 100,000 child-years $^{6}$.

Studies using Maltab carried out a seasonal drowning pattern, which shows that drowning rates increase in the rainy season and reach their peak in the summer (July) with the winter being comparatively free from drowning ${ }^{7}$. An almost similar seasonal pattern was revealed by Bangladesh Health and Injury Survey $(\mathrm{BHIS})^{5}$ after a prior survey, where a sudden drop was found in July and increased in December; however, the reasons were not clear. The BHIS ${ }^{5}$ identified that, in Bangladesh, almost all (97\%) drowning's occurred during the hours of daylight, between $6 a m$ and 6 pm. Based on the previous study, more than three-quarters of drowning's in Bangladesh took place in bodies of water less than 20 metres from the house. Infants drowned in bodies of water very close to the house, within 10 metres $^{5}$. Possibly, exposure to "risky" aquatic sources is the most substantial risk factor for child drowning deaths, as child drowning patterns among various countries indicates that the type of aquatic resource to which the child is exposed is a factor. Death caused by drowning occurred during daily activities in middle-income and low-income countries including washing, 
working, collecting water, playing, and crossing water on the way to school. The aquatic sources are lakes, ditches, water collecting systems, ponds, and rivers, above and below ground, for instance, barrels, wells, buckets and cisterns ${ }^{8}$.

However, child drowning mostly happens in recreational settings in the high-income countries. For older children, this is lakes or rivers that are usually used for swimming, while for younger children it mostly takes place in swimming pools. Although prevention approaches are transferable, different measures and strategies should be undertaken for different types of exposure. In most cases, children are drowned inside or around the home. The probability of drowning occurrence increases for younger children with respect to the proximity of water bodies. A very common place is baths, where children commonly drown when left unattended ${ }^{9}$.

In high-income countries, the drowning of young children occurs when residential pools are not adequately fenced, which is considered to be the strongest factor ${ }^{10}$, whereas, in lower-income countries, it is due to the open bodies of water, such as the presence of wells around the house. For example, a study in an urban area in Mexico found that children living in houses with a well had a seven-fold higher risk of drowning compared to children from homes without a well ${ }^{9}$.

Most infants in Bangladesh aged 12 to 23 months died from drowning in ponds and ditches, which reflects the risk from exposed sources of water near or in homes ${ }^{11}$. A study from Australia also shows that around $78 \%$ of drowning's occur in children under five years who are living on farms, due to the irrigation channels and dams around the farm (Mitchell et al., 2010). Children from under five years old in developed countries commonly drown in recreational swimming pools ${ }^{12}$, 13 , while, in contrast, among poorer communities, drowning occurs in natural bodies of water near their homes, such as reservoirs, rivers, lakes, and ponds ${ }^{14,15}$. More than two-thirds (67\%) of child drowning's occurred when caregivers and mothers were involved in household activities; among which, $16 \%$ were involved in work outside, and $7 \%$ were talking too there or sleeping inside ${ }^{5}$. Almost all (97\%) drowning's occurred during day time between $6 \mathrm{am}$ and $6 \mathrm{pm}^{5}$. Therefore, the purpose of the effectiveness of a mobile SMS intervention to improve the environmental knowledge of parents of children aged under five concerning the prevention of drowning.

\section{Methods}

It was a quantitative study to implement and evaluate an effectiveness mobile-based intervention of the knowledge of parents in respect of childhood drowning prevention. The cluster randomized community trial, was carried out for approximately 24 weeks from August 2015 to December 2015. The villages (or cluster) were the unit of randomization, and an equal number of villages were randomized to one of the two arms (Fig. 1). It included: community trial and Preand post-assessment through face-to-face interviews using a semi-structured questionnaire (Additional file 1). The study population was parents with at least one child aged below five years old in Charghat and Bhayalakshmipur Union of Charghat Upazila, Rajshahi district of Bangladesh. A complete lists of birth registration was collected from the Charghat and Bhayalakshmipur Union administrative units from January to March 2015. The sampling units were individual parents who had at least one child aged below five years old and were eligible according to the inclusion criteria for this study. Detailed study protocol of this study design has been published elsewhere ${ }^{16}$.

The questionnaire for the research has six parts: socio-demographic characteristics, environmental characteristics, parental knowledge, attitude, and practices about childhood drowning, and incident information. Based on the six constructs identified, an initial item pool of 81 statements in the English language was generated. Knowledge has a 10item measure for drowning knowledge, attitude has 13 items, and practices have 25 -items on drowning. The socialdemographic and environmental parts followed the questionnaires by the Centre for Injury Prevention and Research, Dhaka, Bangladesh. The different parts of the questionnaire are shown in Table 1. 
Table 1

Different parts of the questionnaire

\begin{tabular}{|llll|}
\hline Questions & Parts & Number & Score \\
\hline $1-12$ & A:Socio-demographic characteristic & 12 & \\
\hline $13-25$ & B:Environmental characteristics & 13 & \\
\hline $26-39$ & C: Parental Knowledge & 10 & Yes $=$ one mark \\
& & & No $=$ zero marks \\
\hline $40-52$ & D: Parental attitude & 13 & Likert scales: \\
& & & strongly agree $=5$, \\
& & & agree $=4$, \\
& & & Neither agree nor disagree $=3$, disagree $=2$ \\
& & & and strongly disagree $=1$. \\
& & 25 & The total scores is 65. \\
\hline $53-77$ & E: Parental practices & & No = one mark \\
& & & \\
\hline $78-85$ & F: Incident information & & \\
\hline
\end{tabular}

The validity of a measure implies to what extent items measure some aspects of what they are supposed to measure or the extent to which a method tests what it is intended to measure. The content validity of this study was determined by the supervisory committee. The experts checked in which context the representation of any item could be measured. This is a measure of the extent to which questions in the questionnaire include known items/ variables about the subjects of research. In other words, is the questionnaire measuring the intended variables of the research? Does it represent the content? Although the questionnaire contains variables that have been validated internationally among various populations around the world, the content of the questionnaire was further validated by the supervisory committee to ascertain that the questions chosen were representative of the concepts that they are intended to measure or reflect. The first questionnaire included 90 items, which was reduced to 85 after being reviewed by specialists. Two professors in statistics and one population science specialist with experience about Child injuries and research were involved in the validation of the questionnaires. They provided valuable comments that helped to shape the questionnaire to a locally applicable context in view of the socio-cultural background of the people.

\section{Sample Size Estimation}

The formula for hypothesis testing of two group comparison was used ${ }^{17}$.

$N=\{Z 1-a / 2 \sqrt{2} P(1-P)+Z 1-\beta \sqrt{ } 11(1-P 1)+P 2(1-P 2)\}^{2} /(P 1-P 2)^{2}$

P1 $=$ Proportion of illiterate mothers in child drowning cases $=0.34 \&$

$\mathrm{P} 2=$ Proportion of educated mothers in child drowning cases $=0.20^{18}$.

\section{$\mathrm{P}=(\mathrm{P} 1+\mathrm{P} 2) / 2=0.27$}

$\mathrm{Z1}-\mathrm{a} / 2=$ standard error when $\mathrm{a}=0.05(95 \%$ confidence interval $)=1.96$ 
$\mathrm{Z1}-\beta=$ standard error associated with power $=0.842(\beta=0.20)$

Power $(1-\beta)=80 \%$

\section{$\mathbf{N}=157$}

As participants are nested within in villages, a potential design effect $\mathrm{n}$ needed to be considered. The assumed number of participants per village was 20 , and an intra-cluster correlation coefficient of 0.05 could be expected. This would result in a design effect $=1+(\mathrm{m}-1) \times \mathrm{ICC}=1+(20-1) \times 0.05=2$.

Based on the above formula, the required minimum sample size for each group, $\mathrm{n}$ was 314 . To factorise in $10 \%$ attrition (32), the total required per group was 394; hence, a total of 788 parents were required for the sample in both groups.

\section{Data Processing and Analysis}

The Statistical Package for Social Science (SPSS) version 22 was used to analyse the data. Data were collected, checked, cleaned, and data entry was done carefully and successfully. Exploratory data analysis was performed to clean and verify the data in SPSS to ensure that there were no mistakes from wrong data entry, as well as to detect missing data and outliers. Factors with a statistically significant association with environmental variables on childhood drowning prevention knowledge, attitude and practices at the baseline, immediate post intervention and after 3 months follow up in the logistic model ( $\rho$-value of 0.05$)$ controlling for other variables.

\section{Results}

The intervention and control group were compared on environmental characteristics, baseline knowledge. The comparison was done to ensure that the randomization process in this study was able to generate two groups that were compared or comparisons are summarized in Table 1. 
Table 1

Environmental characteristic of the parents

\begin{tabular}{|c|c|c|c|c|}
\hline Factors & $\begin{array}{l}\text { Intervention } \\
\text { Group (\%) }\end{array}$ & $\begin{array}{l}\text { Control } \\
\text { Group (\%) }\end{array}$ & $x^{2}$ & $\rho$-value \\
\hline $\begin{array}{l}\text { Time of Day Child's Move to Outside } \\
\text { 6:00AM-10:00AM } \\
\text { 11:00AM-6:00PM }\end{array}$ & $\begin{array}{l}7(1.8) \\
387(98.2)\end{array}$ & $\begin{array}{l}18(4.6) \\
376(95.4)\end{array}$ & 4.999 & 0.12 \\
\hline $\begin{array}{l}\text { Time of Season } \\
\text { May-August } \\
\text { Rest of the Months }\end{array}$ & $\begin{array}{l}387(98.2) \\
7(1.8)\end{array}$ & $\begin{array}{l}388(98.5) \\
6(1.5)\end{array}$ & 0.078 & 0.50 \\
\hline $\begin{array}{l}\text { Distance of the House from Aquatic } \\
5-10 \mathrm{M} \\
11-20 \mathrm{M} \\
21-30 \mathrm{M} \\
31-50 \mathrm{M}\end{array}$ & $\begin{array}{l}96(24.4) \\
143(36.3) \\
102(25.9) \\
53(13.5)\end{array}$ & $\begin{array}{l}71(18.0) \\
160(40.6) \\
112(28.4) \\
51(12.9)\end{array}$ & 5.202 & 0.15 \\
\hline $\begin{array}{l}\text { Place of Drowning } \\
\text { Ponds } \\
\text { Ditch } \\
\text { Others (Lake, Rivers, Buckets) }\end{array}$ & $\begin{array}{l}348(88.3) \\
40(10.2) \\
6(1.5)\end{array}$ & $\begin{array}{l}292(74.1) \\
88(22.3) \\
14(3.6)\end{array}$ & 6.100 & 0.13 \\
\hline $\begin{array}{l}\text { Daily Activity of Mothers } \\
\text { Households Work } \\
\text { Working in Outside } \\
\text { Others }\end{array}$ & $\begin{array}{l}264(67.0) \\
16(4.1) \\
114(28.9)\end{array}$ & $\begin{array}{l}254(64.5) \\
41(10.4) \\
99(25.1)\end{array}$ & 5.890 & 0.23 \\
\hline
\end{tabular}

For the time of day that children go outside and drown, almost all (98.2\%) parents answered between 11:00am and 6:00 pm for the intervention group; and also almost all (95.4\%) parents answered between 11:00am and 6:00 pm for the control group. There was no association with time day's children's move outside between the intervention and control group. All (98.2\%) the parents answered yes for the intervention group concerning the time of year that drowning occurred being May-August, and $98.5 \%$ of parents answered yes for the control group. There was no association with time season between the intervention and control group. With respect to the distance of the house from the water, $36.3 \%$ of parents stated that the distance of the house from the water was 11-20 metres, $25.9 \%$ parents stated that the distance of the house from the water was 21-30 metres, and $24.4 \%$ parents stated that the distance of the house from the water was 5-10 metres for the intervention group; and 40.6\% parents stated that the distance of the house from the water was $11-20$ metres, $28.4 \%$ of parents stated that the distance of the house from the water was $21-30$ metres, and $18.0 \%$ of parents stated that the distance of the house from the water was 5-10 metres for the control group. There was no association with distance of the house from water between the intervention and control group. The majority (88.3\%) of parents answered that the place of drowning was a pond, and only $10.2 \%$ of parents answered that the place of drowning was a ditch for the intervention group; and $74.1 \%$ of parents answered that the place of drowning was a pond, 
and $22.3 \%$ of parents answered that the place of drowning was a ditch for the control group. There was no association with place of drowning between the intervention and control group. The majority $(67.0 \%)$ of parents answered that the daily activity of mothers involved the household work and only $28.9 \%$ were involved in another activity (gossiping, sleeping) for the intervention group; and for the control group, $64.5 \%$ were involved in household work, and only $25.1 \%$ were involved in another activity (gossiping, sleeping). There was no association with daily activities of mothers between the intervention and control group (Table 1). The results of association with knowledge of parents on drowning prevention and selected socio-demographic and environmental characteristics are presented in Tables 2.

Table 2

The results of chi-Square $\left(x^{2}\right)$ test to drowning prevention knowledge among various environmental variables

\begin{tabular}{|c|c|c|c|c|c|c|c|c|}
\hline Factors & $\begin{array}{l}\text { Immediate } \\
\text { Post }\end{array}$ & $\begin{array}{l}\text { 3-Months } \\
\text { Follow- } \\
\text { up }\end{array}$ & Factors & $\begin{array}{l}\text { Immediate } \\
\text { Post }\end{array}$ & $\begin{array}{l}\text { 3- } \\
\text { Months } \\
\text { Follow- } \\
\text { up }\end{array}$ & Factors & $\begin{array}{l}\text { Immediate } \\
\text { Post }\end{array}$ & $\begin{array}{l}\text { 3- } \\
\text { Months } \\
\text { Follow- } \\
\text { up }\end{array}$ \\
\hline $\begin{array}{l}\text { Time of day } \\
\text { child's move to } \\
\text { outside }\end{array}$ & 1.32 & 0.25 & 11.9 & 0.03 & 3.98 & 0.23 & 9.15 & 0.04 \\
\hline Time of season & 1.14 & 0.28 & 2.18 & 0.32 & 2.90 & 0.44 & 11.9 & 0.05 \\
\hline $\begin{array}{l}\text { Distance of } \\
\text { house from } \\
\text { aquatic bodies }\end{array}$ & 4.28 & 0.23 & 4.97 & 0.21 & 1.23 & 0.56 & 24.9 & 0.03 \\
\hline $\begin{array}{l}\text { Place of } \\
\text { drowning }\end{array}$ & 5.23 & 0.14 & 14.7 & 0.01 & 2.44 & 0.72 & 6.98 & 0.05 \\
\hline $\begin{array}{l}\text { Daily activity of } \\
\text { mothers }\end{array}$ & 2.58 & 0.27 & 10.2 & 0.02 & 2.78 & 0.67 & 10.8 & 0.01 \\
\hline
\end{tabular}

Table 2 reveals that for intervention group, there were significant associations among time of day, time of season, distance of house from water bodies, place of drowning and daily activity of mothers with drowning prevention knowledge after immediate post intervention and after 3-months of intervention.

For control group, there were no significant associations among time of day, time of season, distance of house from water bodies, place of drowning and daily activity of mothers with drowning prevention knowledge after immediate post intervention and after 3-months of intervention. 
Table 3

Environmental factors associated with drowning prevention knowledge of parents at the immediate post and 3-months follow-up between control and intervention group

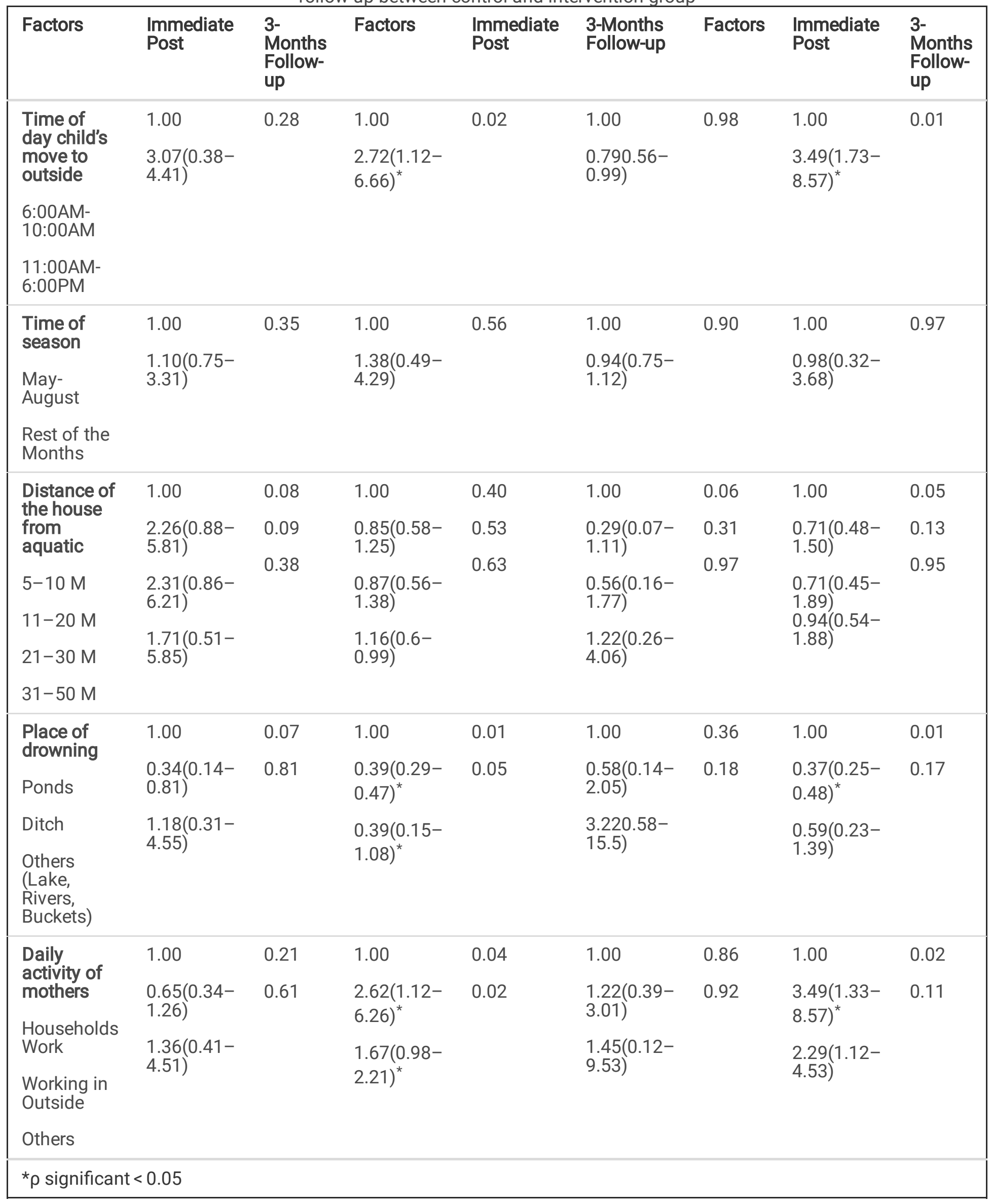


In the context of environmental factors, there was no association with time of day and drowning prevention knowledge at immediate post intervention and after 3-months of intervention for control group. For intervention group, there was a significant association with time of day, and drowning prevention knowledge at the immediate post-intervention and after 3-months of intervention. For the time of day that children go outside and drown, parents answered between 11:00am and $6: 00 \mathrm{pm}$ have $2.72(\mathrm{OR}=2.72,95 \% \mathrm{Cl}=1.12-6.66, \rho$-value $=0.02)$, times greater knowledge about drowning prevention compare to those parents who answered between 6:00am-10:00am after immediate post intervention. Parents who answered between 11:00am and 6:00 pm have 3.49 $(\mathrm{OR}=3.49,95 \% \mathrm{Cl}=1.73-8.57, \rho$-value $=0.00)$ times greater knowledge about drowning prevention compared to those parents answered between 6:00am and 10:00am for the time of day that children go outside and drown after 3-months of intervention (Table 4.6). In the multivariate analysis, there was no association with time of season, and drowning prevention knowledge at immediate post intervention and after 3-months of intervention between control and intervention group. Again, in the multivariate analysis, there was no association with distance of the house from water, and drowning prevention knowledge at immediate post intervention and after 3-months of intervention between control and intervention group. There was no association with place of drowning, and drowning prevention knowledge at immediate post intervention and after 3-months of intervention for control group. For the intervention group, the parents who answered that the place of drowning was a ditch or other (lake, river, buckets $)$ had $0.39(\mathrm{OR}=0.39,95 \% \mathrm{Cl}=0.29-1.48, \rho$-value $=0.00)$ and $0.39(\mathrm{OR}=0.39,95 \% \mathrm{Cl}=0.15-1.08, \rho$-value $=$ $0.05)$ times less knowledge about drowning prevention compared to those parents who answered ponds after immediate post intervention. Those parents who stated that the place of drowning was a ditch had $0.37(\mathrm{OR}=0.37,95 \% \mathrm{Cl}=0.25-$ $0.48, \rho$-value $=0.00$ ) times less knowledge about drowning prevention compared to those parents who answered ponds after 3-months of intervention. Similarly, there was no association with daily activity of mothers, and drowning prevention knowledge at immediate post intervention and after 3-months of intervention for control group. For intervention group, there was an association with daily activity of mothers and drowning prevention knowledge at the immediate post intervention and 3-month follow-up. The parents who were involved in activity outside and other activity (gossiping, sleeping) had $2.62(\mathrm{OR}=2.62,95 \% \mathrm{Cl}=1.12-6.26, \rho$-value $=0.04)$ and $1.67(\mathrm{OR}=1.67,95 \% \mathrm{Cl}=0.98-2.21, \rho$ value $=0.02$ ) times less knowledge about drowning prevention compared to those parents who were involved in household activities after immediate intervention. The parents who were involved in activities outside had 3.94(OR= $3.94,95 \% \mathrm{Cl}=1.33-8.57, \rho$-value $=0.01)$ times less knowledge about drowning prevention compared to those parents who were involved in household activities (Table 3).

\section{Discussion}

The current study found that in multivariate analysis, there was no significant association found for the time of day and drowning prevention knowledge of parents at baseline. However, there was a significant association with time of day and drowning prevention knowledge of parents at the immediate post-intervention. Finally, there was a significant association with time of day and drowning prevention knowledge of parents at the 3-month follow-up intervention. Those parents who said that children go outside and drown between 11:00am and 6:00 pm had more drowning prevention knowledge compared to those parents who said between 6:00am and 10:00am after the intervention. This is similar to the findings of a study conducted by Rahman et al. (2006) ${ }^{7}$ in Bangladesh in Similar results were found with this study, in that there is a common time period (11:00am-2:00 pm) for drowning, which peaks with the period of the heavy rains and monsoon/cyclone season, and, in theory, has a nadir with the winter months. Most drowning's occur in the daylight hours ${ }^{5}$, which could be due to the fact that during this period parents remain very busy with their household activities and pay less attention to their children.

Most of the deaths occur during the day time between $11 \mathrm{am}-6 \mathrm{pm}$ when the child is left unsupervised because the parents are busy with chores. The peak period was in August when children are most at risk for drowning in Bangladesh. During 11:00am-6:00 pm, the parents will provide education in safety, hygiene, nutrition and other health issues of the

Page 9/14 
children to protect from drowning. The findings from the current study showed that in multivariate analysis, there was no significant association with time of season and drowning prevention knowledge of parents at baseline, immediate postintervention or 3-month follow-up intervention. Thus, the null hypothesis was accepted.

There was a clear increase in child drownings in the rainy season, which peaked in the summer (July), while the winter was relatively free of drownings with the lowest month being January. This is similar to the findings of a study conducted in Bangladesh by Rahman et al. (2006) ${ }^{7}$, who observed that drowning in respect of children was prevalent throughout the year; however, about half of drowning deaths occurred during the monsoon, which covers the months from mid-June to mid-October ${ }^{7}$. Furthermore, the $\mathrm{BHIS}^{5}$ indicated that child drowning increased in July and decreased in December. Bangladesh has rivers ponds ditches lakes in addition to the annual monsoon floods and frequent cyclones. Rivers, lakes and ponds abound in Bangladesh, which also has a long coastline, and flooding during the monsoon season leaves many people homeless. Drowning's were considered more frequent in the Bangla month of 'Kartik' (midOctober to mid-November) as they go out for fishing during this period.

According to the UN Children's Fund ${ }^{19}$ in Bangladesh, there were 946 officially reported flood-related deaths since midAugust, with drowning accounting for 816 of them. Over 86 percent of all the deaths were due to drowning, and over 90 percent of these cases were children, mostly under five. The most deaths from drowning occur in July to October time period. This is the season for monsoon and floods in the country. The study also reveals a clear seasonal pattern to drowning. The death rates rise steeply during the summer months when the rainfall is high and shallow ditches and natural holes are frequently filled with flood water. In terms of the distance of the house from water, in multivariate analysis, there was no significant association with the distance of the house from water and drowning prevention knowledge of parents at the baseline. This finding the null hypothesis was rejected of this study.

This is similar to the findings of a study conducted ${ }^{5}$ in Bangladesh in which more than three-quarters of drowning's took place in bodies of water less than 20 metres from the house. Those parents who stated that the distance of the house from water was 5-10 metres had good attitude of drowning prevention compared to those parents who stated that the distance of the house from water was 11-20 metres and 21-30 metres after the interventions and also had good and practices of drowning prevention.

According to the BHIS $(2005)^{5}$, most deaths happen very close to home. An estimated 18,000 children drown each year in Bangladesh. And what is more shocking is the fact that most of the drowning happens within 20 metres of the residence. There was a significant association with the place of drowning and drowning prevention knowledge of parents at the immediate post-intervention. Finally, there was a significant association with the place of drowning and drowning prevention knowledge of parents at the 3-month follow-up intervention. Those parents who considered ponds to be the most common place for drowning incidents had greater knowledge about drowning prevention, compared to parents who considered ditches and other locations (lake, river, buckets) after the interventions.

Based on the findings from the current study, the majority of parents for the intervention group considered ponds to be the most common place of drowning, and $74.1 \%$ of parents for the control group concurred. This is similar to the findings of a study conducted by Rahman et al. (2009) ${ }^{19}$ in Bangladesh, who found that almost all of the respondents identified drowning risks in the ponds and waterways. The common places of drowning were natural bodies of water, such as ponds, ditches, lakes, and rivers. Ponds were the most common place of drowning. More than $40 \%$ of the fatal drowning's occurred in natural bodies of water. It was reported that about half (42.5\%) of the children who drowned were playing in or near the water bodies before drowning ${ }^{7}$.

Based on a previous study, ponds and ditches were considered to be common places for drowning. More than $75 \%$ of drowning's occurred in ponds and ditches. The places of drowning for infants and toddlers were ditches, ponds, tubs and 
drums $^{20}$. Ponds were found to be the most common place of drowning. However, there was no significant association with the place of drowning and drowning prevention knowledge of parents at baseline. This is because, in the villages of Bangladesh, there are numerous ponds around the households, which are used for bathing and washing purposes throughout the year. The chance of drowning deaths is increase with the proximity of water bodies to the household. Children playing in the inflated rivers, canals, ponds, ditches and others water bodies. Most drowning deaths occur in the rural areas children who live near water bodies. In the current study, there was a significant association with the daily activity of mothers and drowning prevention knowledge of parents at the immediate post-intervention and 3-month follow-up intervention. However, there was no significant association with the daily activity of mothers and drowning prevention knowledge of parents at the baseline. Those parents who were involved household activities had more drowning prevention knowledge than those parents who were involved work with outside activities after the postintervention.

The majority of parents were involved in household work, for both groups. This is similar to the findings of a study conducted $^{20,21}$ in Bangladesh in which the information concerning the parents activity prior to the child drowning showed that $70 \%$ of mothers were busy with household activities, and with Rahman et al. (2006) 7,22 who found that at the time of the child drowning, $80 \%$ of the mothers were at home. Moreover, about two-thirds of the drowning deaths occurred when the mothers were involved in household chores. Finally, although allocation concealment, blinding and standardized training of the research assistants concerning research ethics and confidentiality was conducted to minimize the risk of cross-contamination, it was practically impossible to rule out the possibility of contamination due to the pragmatic nature of the study.

\section{Conclusion}

To increase knowledge, mobile phones should be used to let people know about floods during rainy season. Also, unwanted ditches and water bodies nearby house should be protected, children should be kept away from water between $11 \mathrm{am}$ and $2 \mathrm{pm}$ and other family members should watch the children when the mothers are busy performing household activities. This finding is alarming and needs rapid and active measures to prevent such drowning by conducting education programs via mass media, including information about drowning prevention in school curricula and creating group education sessions in primary health care centers. Based on this study, monitoring during 11 am-2 pm (risky time) and fencing of natural bodies of water and education programs via social media such as mobile, TV, radio, newspaper, Facebook, WhatsApp, including water safety information about drowning prevention among parents to increase parental supervision of children in rainy season could be possible prevent more child drowning. More ever, the social media such as radio and TV play an important role in increasing the knowledge childhood drowning prevention as well as child's injuries. Hence, special programmes and training could be increase knowledge about childhood drowning prevention in Bangladesh and should be broadcast on the radio and television networks.

\section{Declarations}

\section{Ethics approval and consent to participate}

All experiments and methods were performed in accordance with relevant guidelines and regulations. The ethical approval for this study was obtained from the University Putra Malaysia (UPM/TNCPI/RMC/1.4.18.1 (JKEUPM)/F2) and Centre for Injury Prevention and Research, Bangladesh. Further, informed written agreement was obtained from all respondents before the data was collected. All the respondents were assured that the data would only be used for research purposes and all answers would be treated as confidential.

\section{Consent to publish}

Page $11 / 14$ 
Not applicable

\section{Availability of data and materials}

Not applicable

\section{Competing interests}

No

\section{Funding}

No

\section{Authors' Contributions}

$\mathrm{MMH}$ and $\mathrm{KKCM}$ are the authors of this manuscript and all authors have read and approved the final manuscript.

1. $\mathrm{KKCM}$ and $\mathrm{MMH}$ conceptualize and designed the research

2. $\mathrm{KKCM}$ and $\mathrm{MMH}$ the formal data analysis and responsible for all analysis

3. All authors are critically revised this manuscript.

\section{Acknowledgements}

Not applicable

\section{References}

1. Peden M \& McGee K. The epidemiology of drowning worldwide. Injury Control and Safety Promotion2003; 10:195199.

2. Peden M, Oyegbite K, Ozanne-Smith J, Hyder AA, Branche C \& Rahman AKMF. et al., editors. World report on child injury prevention. Geneva: World Health Organization2008; 211.

3. BBC News. Swimming lessons in Bangladesh made law to stop drowning, 2015. http://www.bbc.com/news/worldasia-32239442

4. World Health Organization. Global report on drowning: Preventing a leading killer, 2015. Geneva, Switzerland.http://www.who.int/violence_injury_prevention/global_report_drowning/Final_report_full_web.pdf

5. BHIS. Bangladesh Health and Injury Survey, 2005. Dhaka, Bangladesh.

6. Rahman A et al. Bangladesh health and injury survey: report on children. Dhaka, Government of the People's Republic of Bangladesh, ICMH, UNICEF and TASC, 2005.

7. Rahman A, Giashuddin SM, Svanström L et al. Drowning - a major but neglected child health problem in rural Bangladesh: implications for low income countries. International Journal of Injury Control and Safety Promotion2006; 13(2):101-105.

8. Kobusingye OC. The global burden of drowning: Africa. In: Bierens J, ed. Hand book on drowning. Prevention, rescue and treatment. Netherlands, Springer in press 2007.

9. Brenner RA, Trumble AC, Smith GS, Kessler EP \& Overpeck MD. Where children drown, United States, 1995.Pediatrics 2001;108: 85-89. 
10. Fang Y, Dai L, Jaung MS, Chen X, Yu S \& Xiang H. Child drowning deaths in Xiamen city and suburbs, People's Republic of China, 2001-2005. Injury Prevention 2007;13:339-343.

11. Hyder AA, Borse NN, Blum L, Khan R, Arifeen S \& Baqui AH. Childhood drowning in low- and middle income countries: urgent need for intervention trials. J Paediatr Child Health 2008; 44:221-7.

12. Kemp AM \& Sibert JR. Outcome in children who nearly drown: a British Isles study. British Medical Journal 1991; 302:931-933.

13. Fenner PJ, Harrison SL, Williamson JA \& Williamson BD. Success of surf lifesaving resuscitations in Queensland, 1973-1992. Medical Journal of Australia 1995;163: 580-583.

14. Matzopoulos R ed. A profile of fatal injuries in South Africa: third annual report of the National Mortality Surveillance System. Cape Town, Medical Research Council, 2009 (www.mrc.ac.za/crime/nimss2008.pdf, accessed 20 April 2008).

15. Ahmed MK, Rahman M \& Ginneken JV. Epidemiology of child death due to drowning in Matlab, Bangladesh. International Journal of Epidemiology 1999; 28:306-311.

16. Hossain M, Mani KK, Sidik SM, Hayati KS \& Fazlur RA. Randomized controlled trial on drowning prevention for parents with children aged below five years in Bangladesh: a study protocol. BMC Public Health 2015; 15(1):e484e484.

17. Lemeshow S, Hosmer DW, Klar J \& Lwanga SK. Adequacy of sample size in health studies. World Health Organization 1990; 239.

18. Hossain M, Mani KKC, Sherina MS, Hayati KS \& Rahman, AKMF. Social-demographic, Environmental and Caring Risk Factors for Drowning in Bangladesh. BMC Pediatrics 2015; 15:114.

19. UNICEF/TASC. The Alliance for Safe Children's 2014. http://stopdrowning.org/

20. Rahman A, Mashreky SR, Chowdhury SM, Giashuddin MS, Uhaa IJ, Shafinaz S, Hossain M, Linnan M and Rahman F. Analysis of the childhood fatal drowning situation in Bangladesh: exploring prevention measures for low-income Countries. Injury Prevention 2009; 15:75-79.

21. Borse NN, Hyder AA, Streatfield PK, Arifeen SE \& Bishai D. Childhood drowning and traditional rescue measures: case study from Matlab, Bangladesh. Arch Dis Child 2011; 96:675-80.

22. Hossain M, Mani KKC, Sherina MS \& Hayati KS. The Development of an Intervention Package to Prevent Children under Five Years Old Drowning in Rural Bangladesh. ACTA PAEDIATRICA 2016; 105(8):e373-78.

\section{Figures}




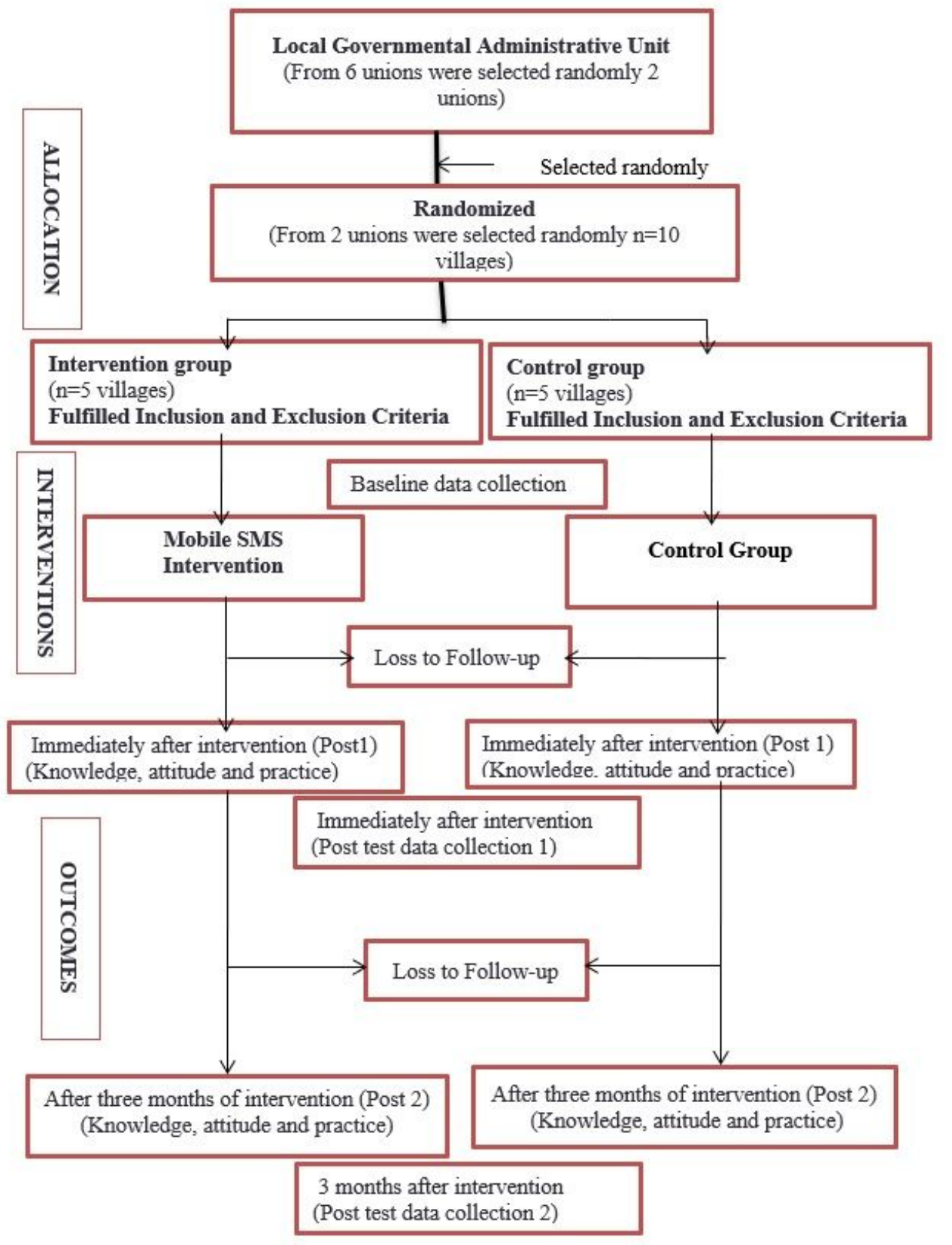

Figure 1

Study flow diagram showing the key components of the intervention

\section{Supplementary Files}

This is a list of supplementary files associated with this preprint. Click to download.

- Questionnaires.docx

- CONSORT2010Checklist.doc 